esa canción. Don Lamberto le habla a Teresa (p. 46) de la alegría que hizo escribir al poeta en la Rima I7 (50): "la he visto y me ha mirado"; y al intentar convencer a don Evaristo, solterón empedernido, de las ventajas del matrimonio (p. 52), cita la Rima 4 (39): "mientras exista una mujer hermosa, / ¡habrá poesía!" Teresa lee el libro de Bécquer en la tensa escena que sigue a la revelación de que ella ha dado a Eugenio la rosa favorita de Lucía (p. 54). Las cuatro hijas de don Buenaventura cantan a coro la Rima 53 (38) (p. 63) ${ }^{14}$. Don Lamberto, convencido de que todo ha terminado entre Teresa y él, recita (p. 74) la primera estrofa de la Rima $4 I$ (26), que, con su "no pudo ser", armoniza perfectamente con la situación. Por último, cuando cae el telón, vuelve a oírse (p. 75), flotando en el aire, la versión coral de "Volverán las oscuras golondrinas".

Para terminar, quisiera mencionar dos recientes producciones cinematográficas sobre la vida de Bécquer. La biografía novelada El gran amor de Gustavo Adolfo Bécquer: Una vida pobre y apasionada, por María Teresa León, proporcionó el argumento para la película argentina del mismo título. El libro y su versión cinematográfica mezclan becquerianamente fantasía y realidad, y exageran el interés de Bécquer por Julia Espín, convirtiéndolo en pasión avasalladora. Alberto de Zavalía dirigió esta película, en la cual actúan Delia Garcés como Julia y Esteban Serrador como Bécquer ${ }^{15}$. El huésped de las tinieblas, producida por la compañía Sagitario Films, se estrenó en Madrid el 20 de septiembre de 1948, y tiene como actores principales a Carlos Muñoz y a Pastora Peña. El argumento, casi enteramente ficticio, gira en torno al idílico amor de Gustavo y Dora, que al final termina con la muerte de los dos jóvenes y su entierro uno al lado del otro.

Harvey L. JohnSON

Indiana University.

\title{
UN EPISODIO DE TIRANO BANDERAS
}

Conocida es la costumbre de Valle-Inclán de incorporar a sus propias obras elementos textuales o reelaborados de obras ajenas. Ya hemos estudiado $\left(\mathrm{NRFH}, 7,1953,53^{6-550}\right.$ ) lo que Valle-Inclán debe, en Tirano Banderas, a dos crónicas que relatan las aventuras y la muerte de Lope de Aguirre. Siempre relacionado con la Novela de Tierra Caliente hemos encontrado otro aprovechamiento. El autor de que Valle se ha servido esta vez es Gerardo Murillo, conocido con el pseudónimo de "Dr. Atl"1, y la obra de cuyos elementos se vale es el cuento La juida ${ }^{2}$. Transcribi-

14 Poco antes, durante el ensayo (p. 59), comenta irónicamente doña Úrsula: "Estamos ya de golondrinas... que no van a volver de verdad por no oír ese coro".

${ }^{15} \mathrm{La}$ biografía de la señorita León está ilustrada con fotografías tomadas de algunas escenas de la película.

${ }^{1}$ Escritor, pintor y crítico de arte, nacido en Jalisco en 1875 . Las obras que nos interesan en conexión con el presente trabajo son: Serie de discursos politicos (1914-1916) y Cuentos de todos los colores, tomo 1.

${ }^{2}$ Esta narración está incluída en el tomo primero de Cuentos de todos los colores, 
mos a continuación el relato mexicano y el episodio de Tirano Banderas (ed. de 1926, pp. 258-261):

\section{La juida}

El rumor blando y monótono de la lluvia sobre un bosque de huizaches. En silencio caminábamos uno tras otro bajo el peso de una grande tristeza, martirizados por la horrible angustia que destroza la vida, cuando un enemigo poderoso nos persigue. El más pequeño movimiento de las ramas nos sobresaltaba. Un pájaro que huía al aproximarnos, nos helaba de terror... Y así caminábamos, entre la lluvia y la zozobra, hasta que se hizo de noche.

En un jacal nos dieron hospitalidad. Indalecio encendió unos leños en el fogón y puso sobre ellos una olla humeada. Mientras el agua hervía, iba deshaciendo con mucho cuidado unos mojados paquetes de café. Tirados sobre el suelo, todos permanecíamos en silencio. El peso de nuestra derrota nos traía aplastados. Indalecio echó el café en la olla y empezó a moverlo con un palo. Después de largo rato dijo con voz grave:

-“iQué mojaos estamos! ¡Pero es mejor l'agua quel sol! Lo pior de todo es la sé."

Nadie respondió. Los seis hombres que habíamos escapado a las balas de los soldados de quién sabe qué "general", no teníamos ganas de entablar conversación.

\section{Tirano Banderas}

$\mathrm{Al}$ otro rumbo del calabozo, algunos prisioneros escuchaban el relato flúido de eses y eles, que hacía un soldado tuerto: Hablaba monótonamente, sentado sobre los calcañares, y contaba la derrota de las tropas revolucionarias, en Curopaitito. Echados sobre el suelo, atendían hasta cinco presos:

-Pues de aquella, yo aún andaba incorporado a la partida de Doroteo Rojas. Un servicio perro, sin soltar el fusil, siempre mojados. Y el día más negro fué el siete de julio: Íbamos atravesando un pantano, cuando empezó la balasera de los federales: No los habiamos visto porque tiraban al resguardo de los huisaches que hay a una mano y a otra, y no más salimos de aquel pantano por la Gracia Bendita. Dende que salimos, les contestamos con fuego muy duro, y nos tiroteamos un chico rato, y otra vez jala y jala y jala, por aquellos llanos que no se les miraba fin... Y un solazo que hacia arder las arenas, y ahí vamos jala y jala y jala y jala. Escapábamos a paso de coyote, embarrándonos en la tierra, y los federales se nos venían detrás. $Y$ no más zumbaban las balas. $Y$ nosotros jala y jala y jala.

La voz del indio, flúida de eses y eles, se inmovilizaba sobre una sola

publicado en 1936. Según me dice su autor, debe de estar incluída también en Cuentos bárbaros (1930), volumen que no he podido consultar. Durante su segunda estada en México (1921), Valle-Inclán conoció personalmente al Dr. Atl, de quien recibió varios escritos relacionados con la revolución mexicana, en la que Valle estaba ya muy interesado. El Dr. Atl no recuerda con exactitud si entre los trabajos que le entregó se encontraba $\mathrm{La}$ juida, como tampoco si ésta fué publicada en periódicos o revistas con anterioridad a la aparición en libro. Ya que tanto Cuentos bárbaros como Cuentos de todos los colores son posteriores a Tirano Banderas, podemos considerar que el texto llegado a manos de Valle debe haber sido proporcionado por el propio Dr. Atl, y existe también la posibilidad de que Valle-Inclán lo leyera en algún periódico o alguna revista que conservó cuidadosamente entre los papeles a los que daba valor de documentos fidedignos. (Para el cotejo he preferido la versión que se encuentra en Cuentos mexicanos de autores contemporáneos, Editorial Nueva España, México, s. f., pp. $79^{-81}$, en que se ha abandonado la ortografía fonética con que había aparecido en Cuentos de todos los colores). 
-“¡Álgame la balacera! Pero jué pior l'otra."

-“¿Cuál?” -preguntó uno.

-“La de po'allá, por Saltío. Nos agarraron entre una bola. Nosotros éramos siete y no los habíamos visto. Nos agarraron de sorpresa, pero les hicimos juego muy duro. Nos aguantamos un chico rato y luego a juir. Y ai vamos por aquel llano que no se le miraba fin... y un solazo que hacía arder la tierra.

"Y ai vamos cuele y cuele y cuele, y cuele y cuele, y los otros detrás, y nosotros a paso de coyote embarrándonos en la tierra, y nomás zumbaban las balas... y nosotros cuele y cuele y cuele..."

(La voz del indio se hacía monótona. A nuestra memoria acudían las más amargas de nuestras desgracias.)

\section{El indio continuó:}

- "Todo el día caminamos al trote, hasta quial meterse el sol, devisamos una pader y corrimos a agazaparnos. Pero los otros nos echaron, y juimos pa'lante a agarrarnos del hocico de una noria. Y aistá otra vez la balacera, pero juerte y tupida, como granizo. $Y$ aquí caiba una bala y allí caiba otra, y empezó a jervir la tierra como cuando en tiempo de secas cain las primeras gotas de la llovizna.

"Los otros tenían ganas de acabarnos y le tupieron juerte, y al poco rato nomás se oiba el esquitero y el esquitero, y el esquitero y el esquitero, como cuando mi vieja me tostaba el máiz.

"El compañero questaba junto a mí, nomás se hacía par un lao y par otro y yo le dije: No las toriés, vale, porqu'es pior. Hasta que le dieron un diablazo en la maceta, y allí se quedó mirando pa'arriba. Y otros compañeros también se quedaron mirando pa'arriba. Y los que quedamos agarramos un vallado, y ai vamos de güelta, siñor, cuele y cuele, y los otros detrás, hasta que se hizo de nochi... Y juimos a amanecer al pie de una sierra donde no había agua, ni qué comer."

El indio quitó la olla del fuego, y nota. El Doctor Atle, famoso orador de la secta revolucionaria encarcelado desde hacía muchos meses, un hombre joven, la frente pálida, la cabellera romántica, incorporado en su hamaca, guardaba extraordinaria atención al relato. De tiempo en tiempo, escribía alguna cosa en un cuaderno, y tornaba a escuchar. El indio se adormecía en su monótono sonsonete:

-Y jala y jala y jala. Todo el día caminamos al trote, hasta que al meterse el sol devisamos un ranchito quemado, y corrimos para agazaparnos. Pero no pudo ser. También nos echaron, y fuimos más adelante y nos agarramos al hocico de una noria. $Y$ ahi está otra vez la balasera, pero fuerte y tupida como granizo. $Y$ aquí caía una bala y allá caía otra, y empezó a hervir la tierra. Los federales tenian ganas de acabarnos, y nos baleaban muy fuerte $y$ al poco rato no más se oia el esquitero, y el esquitero y el esquitero, como cuando mi vieja me tostaba el máiz. El compañero que estaba junto a mí, no más se hacia para un lado y para otro: Motivado que le dije: No las atorees, manís, porque es peor. Hasta que le dieron un diablazo en la maceta, y alli se quedó mirando a las estrellas. $Y$ fuimos al amanecer al pie de una sierra donde no habia ni agua ni máiz, ni cosa ninguna que comer.

Calló el indio. Los presos que formaban el grupo seguían fumando sin hacer ningún comentario al relato, parecía que no hubiesen escuchado. El Doctor Atle repasaba el cuaderno de sus notas, y con el lápiz sobre los labios interrogó al soldado:

- ¿Cómo te llamas?

-Indalecio.

- ¿El apellido?

-Santana.

- ¿De qué parte eres?

-Naci en la Hacienda de Chamulpo. Allí nací, pero todavía chamaco, me trasladaron con una reata de peones a los Llanos de Zamalpoa. Cuando estalló la bola revolucionaria, desertamos todos los peones de las mi- 
mientras agitaba el café dijo con el tono de la más profunda amargura:

- “¿Y todo pa'qué? Tanto correr y tanto susto y tanta hambre ¿pa'qué? ¡Pa'que mi coronel si ande pasiando en automóvil con una vieja que dice qu'es su mujer!"

Removió las brasas con el mismo palo con que había meneado el café, y la luz viva de la hoguera iluminó nuestros rostros con una extraña claridad. nas de un judas gachupín, y nos fuimos con Doroteo.

El Doctor Atle, aún trazó algunas líneas en su cuaderno, y luego recostóse en la hamaca con los ojos cerrados y el lápiz sobre la boca, que sellaba un gesto amargo.

Lo que primero se advierte es que el relato de Indalecio, cuyo nombre se mantiene aunque se le agregue el apellido $^{3}$, pasa con muy pocas alteraciones al texto de Valle-Inclán. Por mucho que se ciña a él, sin embargo, Valle introduce modificaciones, algunas de las cuales acentúan ciertos rasgos que se propone destacar. El vago pero temible enemigo del cuento se precisa en los federales (tropas del gobierno); el rústico pader ('pared') se transforma en un ranchito quemado, índice de destrucción y barbarie ensañada con los pobres e indefensos; el hombre muerto ya no se queda simplemente mirando pa'arriba, sino mirando a las estrellas, tan sin alma como el cielo remoto con su cruel indiferencia, que insistentemente nos muestra la Quinta parte de la novela ${ }^{4}$, las mismas estrellas hacia las cuales tiende las manos la verdadera víctima de todas las tiranías y revoluciones: el indio inerme entre los dos fuegos $^{5}$. Tampoco falta la preocupación por una expresividad acaso más precisa o por un ritmo de mayor intensidad descriptiva. El cuele y cuele y cuele $^{6}$ con que en el cuento se subraya la huída incesante, es reempla-

${ }^{3}$ Debo citar aquí lo que dije a propósito de los nombres propios en "Los americanismos en Tirano Banderas" (Fil, 2, 1950, p. 242): "A la verdad, no siempre importa mucho a quién están referidos los nombres. Lo que sí importa es el nombre mismo y lo que él puede recordar". No importaría mucho el agregado del apellido Santana si éste no evocara de inmediato la figura del general Santa-Anna, caudillo mexicano que intervino persistentemente en la política de su país.

4 "... los dos esposados alzaron la cabeza para hundir una larga mirada en el azu] remoto y luminoso del cielo" (p. 228); "Los pájaros negros hacían círculos en el remoto azul" (p. 237); “...el cielo alto, llameante, cobijaba un astroso vuelo de zopilotes, en la cruel indiferencia de su turquesa" (p. 231).

5 "Disparó el centinela, y suscitóse un tiroteo en toda la línea de avanzadas. Las dos mujerucas quedaron caídas en rebujo, a los flancos del indio, entre los humos de la pólvora, en el aterrorizado silencio que sobrevino tras la ráfaga de plomo. $\boldsymbol{Y}$ el indio, con un agujero en la cabeza, agita los brazos, despidiendo a las últimas es. trellas" (Epílogo, p. 358).

' Según Santamaría, cuele, usado como interjección, expresa entre las clases populares mexicanas "la idea de escapar entre una multitud, por en medio de otras personas". En cuanto a la construcción cuele y cuele y cuele véase lo que de otras similares dice C. E. KANY: "To denote continuity of action, particularly of a persistent or even irritating duration, standard Castilian uses a characteristic popular locution. The formula consists of the singular imperative of the verb $+q u e+$ the imperative or the second future (with or without te): llora que (te) llora or llora que (te) llorarás... Another way of standardly expressing continuity of actions is with gerund 
zado por jala y jala y jala ${ }^{7}$ que transmite la impresión de un esfuerzo continuado y abrumador en que lo tironeado - jalado- hacia una salvación problemática es el propio cuerpo de los fugitivos ${ }^{8}$. Mientras en el cuento el constante repiquetear de las balas se concentra en la construcción "el esquitero y el esquitero, y el esquitero y el esquitero", Valle reduce los dos grupos duales intensivos a una construcción de tres miembros - paralela en cierto modo al "jala y jala y jala"-, pero en la cual la intercalación de la coma después del primer esquitero marca una pausa breve que determina un ritmo de aceleración graduada.

Valle-Inclán aprovecha también algunos detalles que en el cuento tenían menor relieve o importancia relativa. El bosque de huisaches, de valor meramente "escenográfico", se convierte en el escondrijo de los federales. La actitud de los hombres que escuchan el relato y su silencio se mantienen en Tirano Banderas, pero el "tirados por el suelo" es reemplazado por echados, más descriptivo del abandono y del aplastamiento de los oyentes. Si se tiene en cuenta que Valle-Inclán ha preferido poner a los que escuchan no en la relativa libertad del que huye, sino en la reclusión total de Santa Mónica, se comprenderá mejor el porqué del cambio. En cuanto al silencio que sigue a la narración, se acentúa con el "parecía que no hubiesen escuchado", que insinúa, no falta de atención, sino ensimismamiento total en el recuerdo de las desgracias propias a través de las desventuras ajenas. El estado transitorio indicado por la exclamación "iQué mojaos estamos!" se convierte en estado constante a través de la frase "Un servicio perro, sin soltar el fusil, siempre mojados". La amargura que asedia la memoria de los oyentes y se expresa al final del cuento con el desilusionado "¿Y todo pa'qué?" y en la extraña claridad con que la hoguera ilumina los rostros de los

$+y+$ gerund... In some parts of Spanish America (specially frequent in Mexico) we find another locution, possibly a blending of the two just mentioned: llora que llora + llorando y llorando >llora $y$ llora. The verb form in this expression is sometimes felt to be a third person singular or even a reduced form of the gerund (whence it has been called a gerundial imperative) rather than the singular imperative, and regularly has an impersonal value...-Pos, también pa'quéstás ai friegue y friegue..." (American-Spanish syntax, 1945, p. 241). Encuentro otros ejemplos en Juan Rulfo, El llano en llamas, México, 1953: "Dejó al último a la deshijada, que se estuvo brame y brame, hasta que por pura lástima la dejó entrar" (p. 56); "Bueno, me quedaré contigo; pero nomás hasta que amanezca. Y eso si me prometes que llegaremos juntos a Amula, para yo decirles que me pasé la noche ruéguete y ruéguete" (p. 168). Si bien he oído con frecuencia este tipo de locuciones con forma bimembre, sólo he podido recoger una constituída por tres miembros: "Estoy todo el día lave y lave y lave".

7 El verbo jalar significa 'tirar de algo' y también 'ponerse en marcha, en acción, en actividad' (Santamarfa). En lo referente al sentido, la expresión usada por el Dr. Atl en La juida parece más precisa; sin embargo, estilísticamente usada, resulta más efectiva la de Valle. En cuanto a la locución en sí, Valle ha optado por el tipo llora y llora (véase nota anterior).

${ }^{8}$ Adviértase que la expresión jala y jala y jala se usa más insistentemente que la expresión paralela del relato original, con lo que Valle-Inclán consigue acentuar la nota de monotonía. Obsérvese también que Valle ha esquivado muchas formas rústicas o vulgares, aunque haya incorporado al texto algunas palabras que mantienen el sabor americanista. 
hombres se concentra en el "gesto amargo" que sella los labios del Doctor. Finalmente, el hecho de que $L a$ juida estuviera relatada en primera persona llevó quizá a Valle-Inclán a incluir la figura misma del cuentista en el momento de recoger la aventura de labios de Indalecio, con lo cual impidió, por una parte, el desagradable efecto que hubieran producido dos narraciones "autobiográficas" engastadas una en otra dentro del ámbito mayor -aunque impersonal- de la novela; y por otra parte acentuó, si bien con el nombre del autor un poco deformado, la procedencia verdadera del cuento utilizado, y algo de la personalidad del cuentista: "El Doctor Atle, famoso orador de la secta revolucionaria,... guardaba extraordinaria atención al relato" .

La inclusión del cuento en la obra de Valle tiene explicación si atendemos a sus peculiares teorías. Años antes Valle-Inclán había defendido la reproducción casi textual de un pasaje de las Memorias de Casanova en Sonata de primavera. Don Alfonso Reyes nos ha transmitido esa justificación: “... en tiempos en que tales Memorias no andaban todavía en todas las manos, creyó [Valle-Inclán] oportuno aprovechar, a título de documentación auténtica sobre la Italia de la época, unas páginas de Casanova. Galicia, Navarra, México, todos los demás escenarios de sus Sonatas le eran conocidos. No así Italia... A guisa de fragmento de realidad y para envolverlo y mezclarlo abundantemente en su obra de creación propia, dispuso de un pasaje de Casanova" ${ }^{10}$. En el momento de escribir Tirano Banderas Valle ya conocía México; sin embargo, no pudo resistirse ante un texto que le ofrecía mucho de lo que él necesitaba expresar. Y lo intercaló oportunamente. En Santa Mónica están presos revolucionarios de la más distinta especie: el místico (Roque Cepeda), el orador grandilocuente y vacuo (Sánchez Ocaña), el indiferente que abre los ojos cuando entra en la cárcel (Marco Aurelio, el estudiante), el oportunista (Nacho Veguillas), el fanático (el viejo y zahiriente conspirador). Cada uno de ellos manifiesta un modo de pensar o de ser, muestra una arista sentimental. La narración del Dr. Atl proporcionaba un cuadro y daba una opinión y un sentimiento. Valle lo comprendió así y por eso acogió en el lúgubre calabozo las figuras del indio narrador y del Doctor meditabundo. En la aventura y los motivos del uno y en el desencanto y la amargura del otro reunió Valle algo de la fatalidad irremediable de América.

Lindando con el plagio, Valle-Inclán supo esquivarlo. Nos ha presentado - con la firma, diríamos- la verdadera paternidad del texto utilizado. Como lo había hecho con las crónicas y con Casanova. Pero esta vez quizá haya una segunda intención. Valle se había mostrado burlonamente sorprendido de la torpeza de Casares al no descubrir con cuánto cuidado había él indicado una fuente ${ }^{11}$. Ahora indica otra, acaso con mayor claridad, pero sabe que no es fácil descubrirla porque España,

• En el episodio de la novela aparecen, además, elementos nuevos, entre los cuales el más significativo es el breve diálogo en que se expresa una de las causas fundamentales del descontento que ha provocado la reacción de los indígenas.

10 "Las «fuentes» de Valle-Inclán", en Los dos caminos (Cuarta serie de Simpatias y diferencias), Madrid, 1923, pp. 82-83.

11 Véase Alfonso ReYes, op. cit., p. 83 . 
antigua dominadora de América, no conoce bien la literatura ni las preocupaciones de las que fueron sus colonias. La intercalación del cuento es un acierto de interpretación y adaptación, es un juicio admirativo y una demostración de simpatía hacia el Dr. Atl, pero es también probablemente un desafío y una burla, una trampa sin disimulo, para la estrechez mental de ciertos críticos españoles ${ }^{12}$.

El Colegio de México.

Emma Susana Speratti Piñero

\section{NOTA AL CABALLERO DE OLMEDO}

En el acto segundo de El caballero de Olmedo, de Lope (vv. 211219), dice Tello:

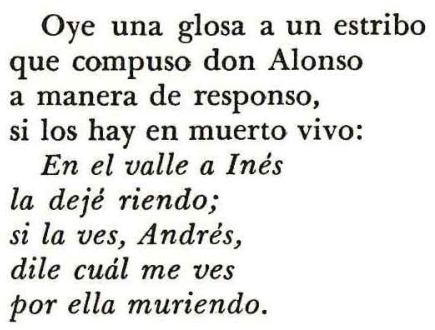

Pudiera pensarse -y yo así lo creí cuando preparé mi edición- que ese villancico era original del propio Lope, puesto que don Alonso está enamorado precisamente de Inés. Sin embargo, en la Flor de romances y glosas y canciones y villancicos..., impresa en Zaragoza en 1578 y reeditada por A. Rodríguez Moñino (Valencia, 1954), se halla, en las pp. 159-162, La glosa de Ynés, con una leve variante:

$$
\begin{aligned}
& \text { En el valle a Ynés, } \\
& \text { la topé riendo; } \\
& \text { si la ves, Andrés, } \\
& \text { dile quál me ves } \\
& \text { por ella muriendo. }
\end{aligned}
$$

Aquí, como en otros muchos casos, Lope se ha limitado a respetar la canción y a añadirle glosa nueva.

Zaragoza.

J. M. Blecua

12 De hecho, sólo la casualidad, y la circunstancia de estar estudiando los distintos elementos de Tirano Banderas, me han permitido hallar esta fuente parcial. En busca de textos que ilustraran el uso del vocabulario americanista en la Novela de Tierra Caliente, encontré la referencia bibliográfica correspondiente a las publicaciones del "Dr. Atl". El nombre me llamó la atención y me hizo pensar que era demasiada coincidencia la semejanza entre Dr. Atl y Doctor Atle. Pero sólo pude salir de dudas al llegar a México, pues me resultó imposible conseguir los libros en Buenos Aires. En cuanto a la actitud de Valle-Inclán al echar mano de un texto ajeno, creo haber dicho lo suficiente para que se entienda que estoy muy lejos de considerarla un plagio descarado. El mismo Dr. Atl, espíritu comprensivo y ágil, la ve como una interpretación de su propio tema. 